\title{
Factors Associated with Help Seeking Behavior of Turkish Women with Urinary Incontinence; A Single Center Cross-Sectional Study
}

\author{
Seyhan SÖNMEZ1, Ersen ERAYDIN1, Yalçın ARICAN1, Ferhan SÖNMEZ1 \\ Denizli, Turkey
}

\section{ABSTRACT}

Objectives: The aim of this study was to determine the patient and urinary incontinence-related factors affecting help seeking behavior of Turkish women with undiagnosed urinary incontinence

STUDY DESIGN: This cross-sectional study was conducted on 490 female patients aged $>18$ years old and were seen in general gynecology outpatients' clinic of Denizli State Hospital. According to referral complaint and results of UDI-6 questionnaire, the participants were classified into 3 groups: Group A: Help seeker patient, Group B: Non help seeker patient and Group C: Continent patient.

RESULTS: Overall urinary incontinence prevalence was $24 \%$. Nearly two thirds $(67 \%)$ of the urinary incontinence patients do not complain about their urinary incontinence symptoms unless they were asked specifically about urinary incontinence. Consultation rate increased with age, duration of incontinence, menopause and the severity of urinary incontinence. After logistic regression analyses, only increasing age, UDI-6 score and severity (SSI) were found to be associated independently with help seeking behavior.

CONCLUSIONS: This study showed that, older, more bothered and severe urinary incontinence patients visit physician and seek medical help. Still nearly half of women who are suffering from clinically significant urinary incontinence remain undiagnosed and untreated. Regardless the visiting reason if its asked specifically for urinary incontinence symptoms by using simple questionnaires, we can reveal and diagnose this patients' group who is suffering from urinary incontinence but yet keeps it disguise.

Keywords: Urinary incontinence, Help seeking behavior, Undiagnosed urinary incontinence

Gynecol Obstet Reprod Med 2017;23(3):153-157

\section{Introduction}

Urinary incontinence (UI) is defined as a complaint of "involuntary loss of urine" by the International Continence Society (ICS) and is one of the most common health problems in women worldwide (1). In a recent review, it has been reported that UI has a wide interval of prevalence between $16.2 \%$ and $81.9 \%$ (2). The prevalence of UI among Turkish women has been reported to be between 20.9 and $35.7 \%(3,4)$.

UI is regarded as a disgraceful situation with a negative ef-

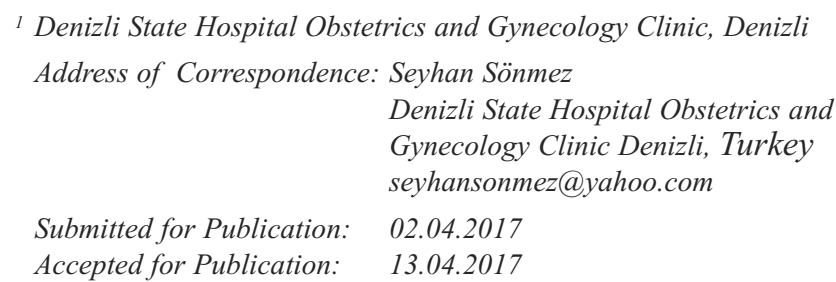

\begin{tabular}{|c|c|}
\hline & Access this article online \\
\hline $\begin{array}{c}\text { Quick Response Code: } \\
\text { nas. }\end{array}$ & Website: www.gorm.com.tr \\
\cline { 2 - 3 } & DOI:10.201613/GORM.2016.699 \\
\hline
\end{tabular}

How to cite this article: Sönmez S. Eraydin E. Arıcan Y. Sönmez F. Factors Associated with Help Seeking Behavior of Turkish Women with Urinary Incontinence; A Single Center Cross-Sectional Study. Gynecol Obstet Reprod Med 2017;23(3):153-157 fect on quality of life, and yet some women with UI tend to keep this complain disguised. Urinary incontinence may cause physical, social, psychological, sexual and economic burden among all age group of women (5). Despite the high prevalence of female UI, majority of incontinent women do not seek medical help. While urinary incontinence is effectively treatable with behavioral, medical, and surgical therapies, a recent review article reported that only one in four women with UI in the United States and one in three women in Europe had sought medical care for UI (6).

In the present study, we objected to determine the patient and UI-related factors affecting the help-seeking behavior of Turkish women with undiagnosed urinary incontinence.

\section{Material and Method}

This cross-sectional study was conducted on 490 female patients aged $>18$ years old and were seen in general gynecology outpatients' clinic of Denizli State Hospital between 31.05.2016 and 01.11.2016. A total of 513 women were invited to participate in our study, 23 declined to answer the questionnaire and hence 490 women were included. The study protocol was approved by ethical committee of Pamukkale University Faculty of Medicine. The exclusion criteria were being under 18 years of age, pregnancy, urinary tract infection and any acute, mental, and auditory disorder. 
The data was collected by four physicians (S.S., E.E, Y.A., F.S.) with face-to-face interview.

Regarding demographic characteristics, age, marital status, educational status, body mass index (BMI), number of delivery, routes of delivery, menopausal status, smoking and associated comorbidities including diabetes mellitus, hypertension and bronchial asthma chronic illnesses, were asked by the interviewers. Following the collection of demographical, clinical and gynecological data, all participants were asked to fill also Turkish version of UDI-6 questionnaire (7) and Sandvik Severity Index (SSI) questionnaire (8). For patients with incontinence, duration of UI was also recorded.

According to referral complaint and results of UDI-6 questionnaire, the participants were classified into 3 groups:

Group A: Patients whose main referral complaint was UI and also classified as a UI patient based on UDI-6 results (Help seeker-UI patient)

Group B: Patients with any referral complaint other than UI but revealed as a UI patients based on UDI-6 results (Non help seeker-UI patient)

Group C: Patients without complaint of UI and approved as continent based on UDI-6 results (Continent patients)

UDI-6 is classified as a grade A recommendation questionnaire for grading and detection of incontinence. Turkish version is also validated by Cam et al. (7) UDI-6 questionnaire consists of 6 questions in ordinal scale, with possible answers of: no, a little, moderately, very much; value of 0 was assigned for the answer "no", 1 for "a little", 2 for "moderately", and 3 for "very much". The total score ranges from 0 to 18 . The average score of 6 questions, which ranges from 0 to 3 is multiplied by $331 / 3$ to put scores on a scale of 0 to 100 . It is considered that there is incontinence in those cases who answered the questions with a value other than no. In these cases, the classification of the type of incontinence is made from the corresponding answers to questions 2 and 3 of the same questionnaire. Specifically, question 2 indicates the presence and severity of urge incontinence and question 3 of stress incontinence. If the answer is yes to both questions, it is classified as mixed incontinence. Pelvic examination and cough test was carried out on the UI participants to verify the type of incontinence. UDI-6 score is a measure of how much a patient is bothered by symptoms due to incontinence. Total UDI-6 score is a single index that indicates overall symptom distress. Higher scores indicate greater symptom severity.

Sandvik severity index (SSI) score was used to characterize the incontinence severity of the participants. The Sandvik Severity Index is a validated measurement of incontinence severity, which has been shown to correlate with the objective measurement of incontinence using a 24-hour pad test. The SSI is comprised of an index score calculated by multiplying the frequency of incontinence by the amount of urine leaked, yielding three categories of severity: slight (1-2), moderate (35) and severe (6-8) (8).

\section{Statistical analysis}

Univariate statistical analyses for categorical variables were performed using Pearson's chi-squared test, or Fisher's exact test, or the Kolmogorov- Smirnov test. For multivariate evaluations, linear logistic regression model and discriminate analysis were used. Continuous data were summarized using mean and standard deviation and Student's t test or MannWhitney U test were used for univariate analyses. Statistical significance was set as $\mathrm{p}<0.05$. Logistic regression analysis was performed to explore the independent variable(s) for help seeking behaviour.

\section{Results}

The prevalence of UI among 490 participants was 24\% $(n=117)$. Of these patients, $39(8 \%)$ were in Group A (helpseeker-UI patient) and 78 (16\%) were in Group B (non-helpseeker-UI patient). There was no difference between Group A and Group B with regard to rates of stress-UI, urge-UI and mix-UI were $(34.2 \%, 31.6 \%$, and 34.2 vs. $21.5 \%, 41.8 \%$, and $36.7 \%$, respectively $\mathrm{p}=0.325$ ). Number of deliveries, route of delivery and co-existent medical problems were similar between Group A and B (Table 1). The mean age of Group A, B and $C$, were $50.2 \pm 12.2$ years, $44.1 \pm 10.5$ years, and $37 \pm 11.0$ years, respectively (Table 1). The prevalence of UI steadily increases along the age in all groups (Table 2). Younger and non-menopausal women were more inclined to keep the symptoms unexpressed and hide their UI complaints (Table 1). The duration of complaints of Help seeker group patients were longer than Non help seeker group patients (33.5 vs. 26.9 months, $\mathrm{p}=0.325$ )

Level of education, type of incontinence and employment status were not associated with help-seeking behavior.

Group A patients had significantly low mean UDI-6 score than Group B patients (47.9 vs. 62.2, $\mathrm{p}<0.001)$.

Incontinence severity was found to be significantly associated with help seeking behavior. According to the SSI, 37.6\% of all UI patients had severe UI. $79.5 \%$ of these patients were bothered and sought medical help. Nevertheless, $20.5 \%$ of severe UI patients were not bothered and didn't seek medical help.

In univariate analysis, consultation rate was associated with age, duration of incontinence, menopause and the severity of UI (Table 2). Therefore, age, level of education, number and types of deliveries, menopausal status, and duration of UI were included in a multiple logistic regression model. After logistic regression analyses, only increasing age, UDI-6 score and SSI score were found to be associated independently with help seeking behavior (Table 3). 
Table 1: Demographic features of the patients

\begin{tabular}{|c|c|c|c|c|}
\hline & $\begin{array}{l}\text { Group A (Help seeker) } \\
\text { n=38 }\end{array}$ & $\begin{array}{l}\text { Group B (Non-help seeker) } \\
n=79\end{array}$ & $\begin{array}{c}\text { Group C (Continent) } \\
n=373\end{array}$ & $\begin{array}{c}p \\
\text { value }\end{array}$ \\
\hline Age, y & $50.2 \pm 12.2^{\mathrm{a}, \mathrm{c}}$ & $44.1 \pm 10.5^{\mathrm{b}, \mathrm{c}}$ & $37.1 \pm 11.0^{a, b}$ & $<0.001$ \\
\hline Number of delivery, $\mathrm{n}$ & $3.2 \pm 2.2^{d, f}$ & $2.4 \pm 1.3^{e, f}$ & $1.9 \pm 1.4^{\mathrm{d}, \mathrm{e}}$ & $<0.001$ \\
\hline Type of delivery & & & & 0.711 \\
\hline No delivery & $0(0.0)$ & $3(3.8)$ & $73(19.6)$ & \\
\hline Vaginal n (\%) & $32(84.2)$ & $62(78.5)$ & $215(57.6)$ & \\
\hline Caesarean n (\%) & $4(10.5)$ & $10(12.7)$ & $56(15.0)$ & \\
\hline Vaginal + caesarean n (\%) & $2(5.3)$ & $4(5.1)$ & $27(7.2)$ & \\
\hline Educational level & & & & 0.059 \\
\hline Illiterate & $9(23.7)$ & $7(8.9)$ & $29(7.8)$ & \\
\hline Primary school & $22(52.9)$ & $50(63.3)$ & $198(53.1)$ & \\
\hline Secondary school & $4(10.5)$ & $7(8.9)$ & $57(15.3)$ & \\
\hline High school & $3(7.9)$ & $10(12.7)$ & $63(16.9)$ & \\
\hline University & $0(0.0)$ & $5(6.3)$ & $26(7.0)$ & \\
\hline Menopausal status n (\%) & $17 / 38(44.7)$ & $21 / 79(26.6)$ & $57 / 373(15.3)$ & $<0.001^{*}$ \\
\hline Smoking $n(\%)$ & $8 / 38(21.1)$ & $17 / 79(21.5)$ & $37 / 373(9.9)$ & 0.002 \\
\hline
\end{tabular}

a: $p<0.001, b: p<0.001, c: 0.016, d: p<0.001, e: p=0.012, f: p=0.013$, * Linear-by-linear association

Table 2: Help seeker and non-help seeker patients' characteristics

\begin{tabular}{|c|c|c|c|}
\hline & $\begin{array}{l}\text { Group A (Help seeker) } \\
\qquad \mathrm{n}=38\end{array}$ & $\begin{array}{l}\text { Group B (Non-help seeker) } \\
\text { n=79 }\end{array}$ & $p$ value \\
\hline Age category & & & $0.032^{*}$ \\
\hline$<30, \mathrm{n}(\%)$ & $2(5.3)$ & $10(12.7)$ & \\
\hline $30-39, \mathrm{n}(\%)$ & $6(15.8)$ & $19(24.1)$ & \\
\hline $40-49, \mathrm{n}(\%)$ & $10(26.3)$ & $24(30.4)$ & \\
\hline$>50, \mathrm{n}(\%)$ & $20(52.6)$ & $26(32.9)$ & \\
\hline Type of incontinence & & & $0.325^{*}$ \\
\hline Stress, n (\%) & $13(34.2)$ & $17(21.5)$ & \\
\hline Urge, n (\%) & $12(31.6)$ & $33(41.8)$ & \\
\hline Mix, $n(\%)$ & $13(34.2)$ & $29(36.7)$ & \\
\hline Duration of incontinence, month & $33.5 \pm 33.8$ & $26.1 \pm 26.9$ & 0.245 \\
\hline UDI score & $62.2 \pm 13.1$ & $47.9 \pm 16.4$ & $<0.001$ \\
\hline Severity of incontinence & & & $<0.001$ \\
\hline Mild UI, n (\%) & $1(3)$ & $33(97)$ & \\
\hline Moderate UI, n (\%) & $3(7.7)$ & $36(92.3)$ & \\
\hline Severe UI, n (\%) & $35(79.5)$ & $9(20.5)$ & \\
\hline
\end{tabular}

Linear-by linear association

Table 3: Logistic regression analyses for independent predictors of help seeking behavior

\begin{tabular}{lccc}
\hline & Odds ratio & $95 \% \mathrm{Cl}$ & P value \\
\hline Age, year & 0.93 & $0.84-0.97$ & 0.026 \\
Educational level & 1.17 & $0.66-2.09$ & 0.583 \\
Number of delivery, $\mathrm{n}$ & 1.02 & $0.73-1.42$ & 0.926 \\
Type of delivery & 0.87 & $0.39-1.92$ & 0.731 \\
Smoking status & 0.65 & $0.20-2.14$ & 0.651 \\
Menopause status & 1.12 & $0.29-4.43$ & 0.868 \\
Duration of incontinence symptom & 0.99 & $0.97-1.01$ & 0.242 \\
UDI- 6 score & 0.94 & $0.91-0.97$ & 0.019 \\
Sandvik Severity Index (SSI) score & & & 0.001 \\
$\quad$ Slight & 4529.4 & $48.4-423804.2$ & $<0.001$ \\
$\quad$ Moderate & 4757.1 & $16.2-1398396.2$ & 0.003 \\
\hline
\end{tabular}

${ }^{*}$ Reference category 


\section{Discussion}

This study showed that nearly two thirds of the UI patients do not complaint about their UI symptoms unless they were asked specifically about UI. Especially younger and less severe UI patients were inclined to hide their complaint.

Although all patients who visited general gynecology outpatient clinic had an opportunity to express their UI complaints, yet only less than one third (32.5\%) of them mentioned about it. $67 \%$ of UI women hide their complaints and therefore they would have been undiagnosed and untreated. Similar low consultation rates (13-38-\%) were also shown in different studies (9-11).

Many risk factors for non-help seeking behavior of incontinent women was described. There are conflicting data about effect of age on consultation rate. Some studies suggested no effect $(12,13)$, on the contrary a few indicated that older people are frequently not assessed and treated partly due to lack of awareness among both patients and professionals $(14,15)$ and majority of studies similarly showed an increase in consultation rate $(16,17)$. Increasing rate with increasing age was supposed to be a cumulative effect.

Women's perceptions of the bothersomeness of their UI was associated with help seeking behavior. It has been shown that how bothersome people find UI is a stronger predictor of help seeking than the severity of UI (18). UDI-6 score is a measure of how much a patient is bothered by symptoms of incontinence. If we use UDI-6 score as a degree of bothersomeness UDI-6 score was significantly higher in help seeker patients group representing more disturbance.

Perceived severity of UI is a predictor of help seeking behavior among incontinent women (19). One Turkish study showed that frequency, severity and type of UI were independent factors for predicting bothersomeness while another Norwegian study found that increasing age, severity and UI duration were also significantly associated with consultation rate $(4,17)$.

Our study confirmed that women's help seeking behavior is strongly associated with UI severity. Nearly $80 \%$ of "severe UI" patients visited physician for their complaints and sought medical help in contrast to $97 \%$ of "mild UI" patients, who preferred to hide their complaints and did not seek medical help. Although there was no standardized definition of UI severity, according to analysis of previous 15 studies, $29-55 \%$ of "severe UI" and 3-60\% of all UI patients visited a physician for their complaints (6). As in previous EPINCOT study(17) if we accept significant UI as moderate or severe UI, still 54\% of the significant UI patient didn't seek help.

We conduct this study on participants who visited gynecology outpatient clinics so all patients had a chance to express their UI complaints. It has shown that older, more both- ered and severe UI patients visit physician and seek medical help. In daily practice, we see and treat only this patients' group. But still nearly half of women who are suffering from clinically significant UI remain undiagnosed and untreated. Usually we classify this group as non-help seeker. Actually, these patients are only undiagnosed. We know that there are too many barriers for expressing UI symptoms such as embarrassment, lack of knowledge, hesitation and fear to consult a physician. Regardless the visiting reason if its asked specifically for UI symptoms by using simple questionnaires, we can reveal and diagnose this patients' group that is suffering from UI but yet keeps it disguise.

This study has some limitations: firstly, the study was a cross sectional study, thus we could not show a cause and effect relationship. But we could describe associations between different factors and help seeking behavior. Secondly, it was not a population based study, so its findings cannot be generalized to the normal population. Nevertheless, it describes the real life data, and could be accepted as representative data of daily life. Thirdly, definition of the type of UI was based on their responses to UDI-6 questionnaire and result of cough test, no urodynamic test was carried out to verify the type of UI. Despite these limitations, it also has some strength. This study was primarily designed to determine the prevalence of nonhelp seeking behavior of UI patients and related risk factors. It was conducted on women visiting gynecology outpatient clinics, so it could show more accurately the patients non-help seeking attitude than the postal or telephone questionnaires. In contrast to postal or telephone questionnaires which are assessing UI as a major driving motive of help seeking behavior, we aimed to evaluate the help seeking/non-help seeking behavior for UI irrespective of the reason of outpatient clinic visit. We also used recommended and valid questionnaires (UDI-6 and SSI) for diagnosis of UI type and severity.

In conclusion, the consultation rate of UI at our country and all over the world is still very low. Our data suggest that, the patients consider UI embarrassing and assume that the UI to some degree is a "normal" result of ageing process. Irrespective of the reason to visit a physician, patients are unwilling to speak about UI problems unless it is "severe" and/or extremely bothersome. As a physician we should keep in mind that the patients we see at outpatient clinics are only a small proportion of women who are suffering from clinically relevant UI. To reduce the underdiagnoses and thus under treatment, and to increase the quality of life of our patients, we should actively look for UI, take actions to increase the awareness and inform the patients about the therapeutic options.

\section{References}

1. Abrams P, Cardozo L, Fall M, Griffiths D, Rosier P, Ulmsten $U$, et al. The standardisation of terminology of lower urinary tract function: report from the Standardisation Sub-committee of the International 
Continence Society. Am J Obstet Gynecol 2002;1(187): 116-26.

2. Kwon BE, Kim GY, Son YJ, Roh YS, You MA. Quality of life of women with urinary incontinence: a systematic literature review. Int Neurourol J 2010;14(3):133-8.

3. Dursun P, Dogan NU, Kolusari A, Dogan S, Ugur MG, Komurcu O, et al. Differences in geographical distribution and risk factors for urinary incontinence in Turkey: analysis of 6,473 women. Urol Int 2014;92(2):209-14.

4. Cetinel B, Demirkesen O, Tarcan T, Yalcin O, Kocak T, Senocak M, et al. Hidden female urinary incontinence in urology and obstetrics and gynecology outpatient clinics in Turkey: what are the determinants of bothersome urinary incontinence and help-seeking behavior? Int Urogynecol J 2007;18(6):659-64.

5. Kocak I, Okyay P, Dundar M, Erol H, Beser E. Female urinary incontinence in the west of Turkey: prevalence, risk factors and impact on quality of life. Eur Urol 2005; 48(4):634-41.

6. Minassian VA, Drutz HP, Al-Badr A. Urinary incontinence as a worldwide problem. Int J Gynecol Obstet 2003;82 (3):327-38.

7. Cam C, Sakalli M, Ay P, Cam M, Karateke A. Validation of the short forms of the incontinence impact questionnaire (IIQ-7) and the urogenital distress inventory (UDI6) in a Turkish population. Neurourol Urodyn 2007; 26(1):129-33.

8. Sandvik H, Seim A, Vanvik A, Hunskaar S. A severity index for epidemiological surveys of female urinary incontinence: comparison with 48-hour pad-weighing tests. Neurourol Urodyn 2000;19(2):137-45.

9. O’Donnell M, Lose G, Sykes D, Voss S, Hunskaar S. Helpseeking behaviour and associated factors among women with urinary incontinence in France, Germany, Spain and the United Kingdom. Eur Urol 2005;47(3):385-92.

10. Kinchen KS, Burgio K, Diokno AC, Fultz NH, Bump R,
Obenchain R. Factors associated with women's decisions to seek treatment for urinary incontinence. J Women's Health 2003;12(7):687-98.

11. Perera J, Kirthinanda DS, Wijeratne S, Wickramarachchi TK. Descriptive cross sectional study on prevalence, perceptions, predisposing factors and health seeking behaviour of women with stress urinary incontinence. BMC Women's Health 2014;14(1):78.

12. Burgio KL, Ives DG, Locher JL, Arena VC, Kuller LH. Treatment seeking for urinary incontinence in older adults. J Am Geriatr Soc 1994;42(2):208-12.

13. Herzog A, Fultz NH, Normolle DP, Brock BM, Diokno AC. Methods used to manage urinary incontinence by older adults in the community. J Am Geriatr Soc 1989;37 (4):339-47.

14. Wagg A. Urinary incontinence in older people: an overview. Medicine 2013;41(1):20-3.

15. Vethanayagam N, Orrell A, Dahlberg L, McKee KJ, Orme S, Parker SG, et al. Understanding help-seeking in older people with urinary incontinence: an interview study. Health Soc Care Community 2017;25(3):1061-9.

16. Wallner LP, Porten S, Meenan RT, O'Keefe Rosetti MC, Calhoun EA, Sarma AV, et al. Prevalence and severity of undiagnosed urinary incontinence in women. Am J Med 2009;122(11):1037-42.

17. Hannestad YS, Rortveit G, Sandvik H, Hunskaar S. A community-based epidemiological survey of female urinary incontinence: The Norwegian EPINCONT Study. J Clin Epidemiol 2000;53(11):1150-7.

18. Xu D, Wang X, Li J, Wang K. The mediating effect of 'bothersome' urinary incontinence on help seeking intentions among community-dwelling women. J Advanc Nurs 2015;71(2):315-25.

19. Koch LH. Help seeking behaviors of women with urinary incontinence: an integrative literature review. J Midwife Women's Health 2006;51 (6):e39-e44. 